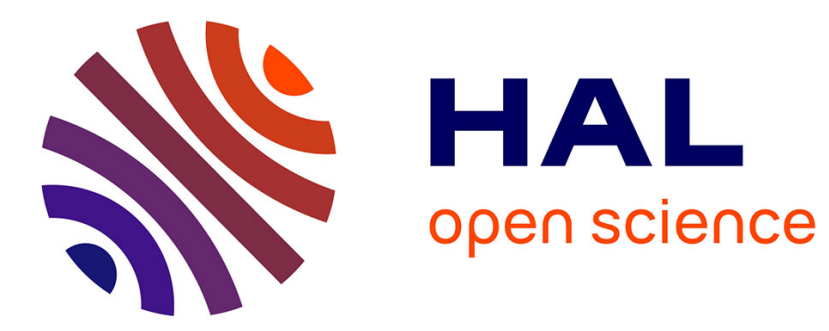

\title{
On the precautionary motive for savings and prudence, in an EU and a NEU framework
}

Alain Chateauneuf, Ghizlane Lakhnati, Eric Langlais

\section{To cite this version:}

Alain Chateauneuf, Ghizlane Lakhnati, Eric Langlais. On the precautionary motive for savings and prudence, in an EU and a NEU framework. 2005. halshs-00194667

\section{HAL Id: halshs-00194667 \\ https://shs.hal.science/halshs-00194667}

Submitted on 7 Dec 2007

HAL is a multi-disciplinary open access archive for the deposit and dissemination of scientific research documents, whether they are published or not. The documents may come from teaching and research institutions in France or abroad, or from public or private research centers.
L'archive ouverte pluridisciplinaire HAL, est destinée au dépôt et à la diffusion de documents scientifiques de niveau recherche, publiés ou non, émanant des établissements d'enseignement et de recherche français ou étrangers, des laboratoires publics ou privés. 

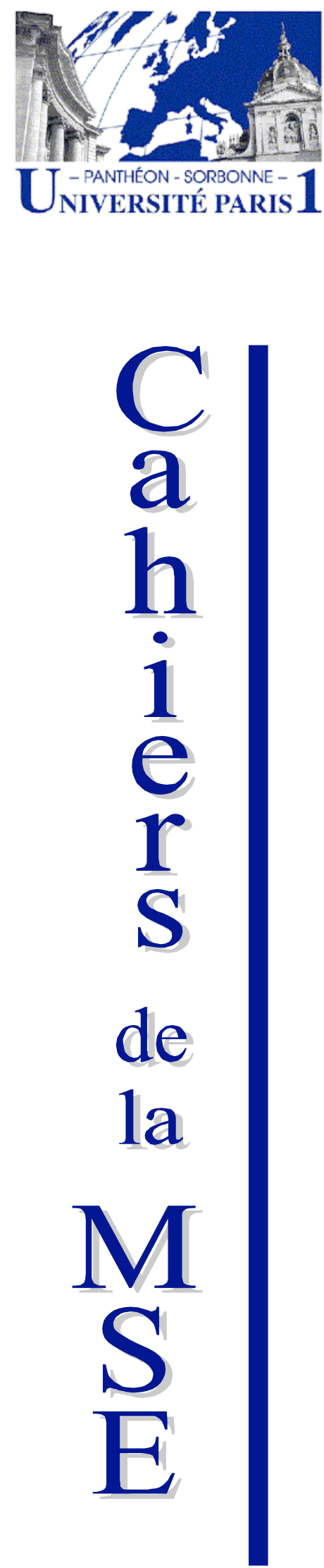

On the precautionary motive for savings and prudence in an EU and a NEU framework

\author{
Alain Chateauneuf, CERMSEM \\ Ghizlane LAKHNATI, CERMSEM \\ Eric LANGLAIS, GAME
}

2005.34 


\title{
On the precautionary motive for savings and prudence, in an EU and a NEU framework
}

\author{
A.Chateauneuf, G.Lakhnati ${ }^{\dagger}$ and E.Langlais ${ }^{\ddagger}$
}

\begin{abstract}
Résumé
Dans ce papier nous traitons le problème de base de consommation à deux périodes où l'utilité de la consommation en première et deuxième période, respectivement: $v$ et $u$, est supposée concave. Considérant l'hypothèse usuelle de l'identité de $u$ et $v$, nous montrons que la prudence est entièrement caractérisée par la convexité de $u^{\prime}$ dans le modèle EU. Plus intéressant, nous montrons que pour le modèle RDEU, la prudence est entièrement caractérisée par la convexité de $u^{\prime}$ et le pessimisme fort. Le papier finit en montrant que pour un décideur RDEU adversaire fort du risque, le pessimisme strict implique la prudence faible locale, quel que soit le signe de $u^{\prime \prime \prime}$.
\end{abstract}

Mots Clés: Modèle EU, Modèle RDEU, Aversion forte pour le risque, Pessimisme, Prudence et Prudence locale faible.

Classification JEL: D10, D80, D90, E21.

\begin{abstract}
In this paper we deal with the basic two-period consumption saving problem where the first and second period consumption utility, respectively $v$ and $u$ is assumed to be concave as usually. Considering the usual assumption of identity of $u$ and $v$, we show that prudence is fully characterized by the convexity of $u^{\prime}$ in the EU model. More interesting we prove that for the RDEU model, prudence is fully characterized by the convexity of $u^{\prime}$ and strong pessimism. The paper ends by showing that for a strong risk averse RDEU decision maker, strict pessimism allows local weak prudence, whatever the sign of $u^{\prime \prime \prime}$.
\end{abstract}

Keywords: EU Model, RDEU Model, Strong Risk Aversion, Pessimism, Prudence and Local Weak Prudence.

JEL Classification: D80, E21.

\footnotetext{
${ }^{*}$ CERMSEM-Université de Paris 1, 106-112 Boulevard de l'Hôpital, 75647 Paris Cedex 13, France. E-mail: Chateauneuf@univ-paris1.fr

${ }^{\dagger}$ CERMSEM-Université de Paris 1, 106-112 Boulevard de l'Hôpital, 75647 Paris Cedex 13, France. E-mail: Lakhnati@univ-paris1.fr.

${ }^{\ddagger}$ GAME (FRE 2881 du CNRS)-Université de Nancy 2, 13, Place Carnot, 54035 Nancy Cedex, France. E-mail: Eric.Langlais@univ-nancy2.fr
} 


\section{Introduction}

The most popular model which has been used to analyze consumption decisions under risk is the basic two-period "Consumption-Saving" model where the decision maker (DM) is supposed to be a risk averse expected utility maximizer (see, Leland [12] and Sandmo [17]). An important question to ask is: how an agent's saving is affected by an increase in risk. If the individual may want to increase his saving in the face of risk, his reaction indeed is associated with the notion of "Precautionary saving".

Kimball [11] has proposed to define as a prudent DM any individual who displays a positive motive for precautionary saving - that is: a prudent DM increases his saving when the risk on his future income increases. Since Leland [12], Drèze and Modigliani [9], Sandmo [17], it is well known that in the basic two-period model, the convexity of the marginal utility of second period is a sufficient condition for a risk averse DM to be prudent. Nevertheless, the necessity of the convexity of the marginal utility has not yet been proved. This remark also applies to the analysis of consumption decisions in the context of non expected utility decision models (Demers and Demers [7], Etner [10]).

In this paper, we revisit the basic two-period consumption/saving decisions model, where in the first period, the consumer is endowed with an initial (non risky) wealth $w$, while in the second period, his income is supposed to be risky, represented by a random variable $Y$, with a known probability distribution. We consider necessary and sufficient conditions for prudence, first in the Expected utility case and then in the Rank Dependant one. For its main part, the paper also focuses on the case where the DM is facing a large increase in risk, according to the popular criterion used by economists of the second stochastic dominance (SSD) order. But it is well known that Arrow [3] has shown that in fact, a risk averse EU DM facing risky prospects with small variance behaves locally as a risk neutral DM. Segal and Spivak [18] define this attitude as second order risk aversion, and show that in contrast, any RDEU DM risk averse in the strong sense, displays first order risk aversion (i.e. risk aversion for small risks). Hence, in the last part of the paper, we focus on the precautionary motive for saving when the future income is seen as such a small risk.

The paper is structured as follows. Sections 2 and 3 present the concepts used for our theoretical model. In section 4 we study the consumption/saving problem in the Expected Utility model and we show that, if the agent keeps the same function of utility in both periods, convexity of the (second period) marginal utility (i.e. $u^{\prime \prime \prime} \geq 0$ ) is necessary and sufficient for prudence. Then relaxing the assumption of an identical utility index in both period, we consider two particular cases for which the DM will be prudent whatever the sign of $u^{\prime \prime \prime}$. Section 5 deals with the Rank Dependent Expected Utility model. We prove that if the agent considers the same concave utility function in both periods then under Inada conditions, the DM is prudent if and only if he is strictly risk averse in the strong sense and $u^{\prime \prime \prime} \geq 0$.

Section 6 introduces the case of a small (second period) income risk. The DM will be in some sense "prudent", if when facing a small actuarially neutral risk, then he increases his saving. We will term his attitude as a locally weakly pru- 
dent behavior. We will prove that for the RDEU model, if a DM is strictly risk averse and strictly pessimistic, he will be locally weakly prudent whatever the sign of $u^{\prime \prime \prime}$ is, a behavior not necessarily verified by a strictly risk averse EU DM. Section 7 concludes.

\section{Risk and increase in risk: the framework}

Let us begin with some basic notations and definitions. Since the topics of the paper is the analysis of savings decision under risk, when we will speak in the sequel of a situation as a risky one, we mean the following.

We consider a decision maker (DM) faced with choices among risky assets $X$, the set $\mathbb{V}$ of such assets consisting of all bounded real random variables defined on a probability space $(S, \mathcal{A}, P)$ assumed to be sufficiently rich to generate any bounded real-valued random variables. $\mathrm{S}$ is the set of states of nature, $\mathcal{A}$ is a $\sigma$-algebra of events, and $\mathrm{P}$ is a $\sigma$-additive non atomic probability measure on $(S, \mathcal{A})$.

For $X \in \mathbb{V}, F_{X}$ will denote the cumulative distribution function of $X: F_{X}(t)=$ $P(X \leq t)$, and $E(X)$ the mathematical expectation of $X: E(X)=\int x d F_{X}(x)$. A finite discrete random variable $X$, will be also denoted as:

$\mathcal{L}(X)=\left(x_{1}, p_{1} ; x_{2}, p_{2} ; \ldots ; x_{n}, p_{n}\right)$, with $p_{i} \geq 0, \sum_{i=1}^{n} p_{i}=1$, and assuming that $x_{1} \leq x_{2} \leq \ldots \leq x_{n}$ without loss of generality.

Now, let $\succeq$ be the preference relation over $\mathbb{V}$ of a decision maker (DM thereafter). Thus for any pair of real random variables $X, Y \in \mathbb{V}: X \succeq Y$ means that for the DM, $X$ is at least as good as $Y$.

The relation $\succeq$ is assumed to be a weak order (i.e.: transitive and complete preference ordering $)^{1}$ and also monotone (i.e.: $\left.X \succeq Y+\epsilon . S^{*}, \epsilon>0 \Rightarrow X \succ Y\right)^{2}$.

One of the most popular criterion used by economists to represent the idea of an increase in risk, is the second stochastic dominance order (SSD).

By definition, for any $X, Y \in \mathbb{V}$, we say that $Y$ is dominated by $X$ with respect to the SSD order (that is $Y$ is riskier than $X$ ) if:

$$
\int_{-\infty}^{t} F_{Y}(x) d x \geq \int_{-\infty}^{t} F_{X}(x) d x, \forall t \in \mathbb{R}
$$

When we constrain $X$ and $Y$ to have the same mean (i.e.: $E(X)=E(Y)$ ), then $Y$ is said to be a Mean Preserving Increase in Risk (MPIR thereafter) of $X$, denoted $Y$ MPIR $X$.

As shown earlier by Rothschild and Stiglitz [14], this notion of MPIR leads to a very natural definition for the behavioral concept of aversion to risk.

\footnotetext{
${ }^{1} \mathrm{~A}$ non trivial weak order is a relation between the elements of $\mathbb{V}$ which is:

- Transitive: $\forall X, Y, Z \in \mathbb{V}, X \succeq Y, Y \succeq Z$ implies $X \succeq Y$.

- Complete: $\forall X, Y \in \mathbb{V}, X \succeq Y$ or $Y \succeq X$.

${ }^{2}$ For $A \in \mathcal{A}$, De Finetti 's use of $A^{*}$ to denote the characteristic function of $A:\left[A^{*}(s)=\right.$ 1 if $s \in A, A^{*}(s)=0$ if $\left.s \notin A\right]$ will be adopted.
} 
Definition 2.1 (Rothschild and Stiglitz [16])

The DM is strongly risk averse if: $\forall X, Y \in \mathbb{V}$, such that $Y M P I R X$, then $X \succeq Y$.

Note that economists are usually more familiar with the definition of risk aversion initially proposed by Pratt and Arrow:

Definition 2.2 (Arrow [2], Pratt [13])

The DM is weakly risk averse if $\forall X \in \mathbb{V}, E(X) . S^{*} \succeq X$.

Trivially, given that $X M P I R E(X)$ for any $X$, risk aversion in the strong sense of Rothschild and Stiglitz implies risk aversion in the weaker sense of Arrow-Pratt.

\section{The representation of the decision maker's prefer- ences: Assumptions}

Following the descriptive solution of Allais [1], Quiggin [14] and Yaari [20] have proposed a generalization of the Expected Utility approach rationalizing the basic idea that facing with a risk associated to a known probability distribution, a DM distorts the probabilities in a subjective manner that depends on the relative ranking of the payments to which they are associated. Several authors as for instance Chateauneuf [4] and Wakker [19] have proposed alternative axiomatics that lead to a Rank Dependent Expected Utility (RDEU thereafter) representation of the preferences of such a DM.

The fundamental aspect of the RDEU model is the weakening of the independence axiom which is central to the Expected Utility model (EU thereafter). It is replaced by the comonotonic sure thing principle. Let us recall the definition of comonotonicity:

Definition 3.3 Two random variables $X$ and $Y$ are comonotonic if $\forall s, s^{\prime} \in S$, then

$\left(X(s)-X\left(s^{\prime}\right)\right)\left(Y(s)-Y\left(s^{\prime}\right)\right) \geq 0$.

The RDEU model can be defined as follows: If the preferences of the DM respect the axioms of the RDEU model ( $\succeq$ on $\mathbb{V}$ is transitive, complete and monotone, satisfies comonotonic sure thing principle and some additional technical properties), then there exists two functions:

i) $u: \mathbb{V} \rightarrow \mathbb{R}$ which is a continuous and increasing utility function, which is unique up to a positive affine transformation.

ii) $f:[0,1] \rightarrow[0,1]$ which is a continuous and increasing probability transformation function, satisfying: $f(0)=0$ and $f(1)=1$,

such that $\forall X, Y \in \mathbb{V}, X \succsim Y \Leftrightarrow E_{f_{o P}}(u(X)) \geq E_{f_{o P}}(u(Y))$ where $\forall Z \in \mathbb{V}$ :

$$
E_{f o P}(u(Z))=\int_{-\infty}^{0}\left[f(P(u(Z)>t)-1] d t+\int_{0}^{+\infty} f(P(u(Z)>t) d t\right.
$$


In the case where we focuse the attention on discrete random variables, the value function $E_{f}(u(Z))$ may be written as:

$$
E_{f o P}(u(Z))=u\left(z_{1}\right)+\sum_{i=2}^{n}\left[u\left(z_{i}\right)-u\left(z_{i-1}\right)\right] f\left(\sum_{j=2}^{n} p_{j}\right)
$$

Then, it is easy to see that the RDEU representation of the preferences is based on an intuitive behavioral principle: the DM takes for sure the utility of the worst outcome $u\left(z_{1}\right)$ and weights the successive additional increases of the utility $u\left(z_{i}\right)-u\left(z_{i-1}\right)$ by $f\left(\sum_{j=i}^{n} p_{j}\right)$, which may be understood as a subjective transformation of the probability to obtain at least the outcome $z_{i}$.

While the RDEU model is a generalization of the EU model, it may also encompass the Dual Theory of Yaari. On one hand, if the perception function $f$ is the identity function, then $E_{f o P}(u(Z))=E(u(Z))$. On the other hand, if the utility function $u$ is the identity function, then $E_{f_{o P}}(u(Z))=E_{f_{o} P}(Z)$ which is the Yaari functional. Finally, if both the risk perception function and the utility function are the identity, then $E_{f o P}(u(Z))$ is simply the expected value $E(Z)$ of the random variable.

It is worth noting that for a RDEU DM, risk aversion in the strong sense is characterized by the concavity of $u$ and the convexity of $f$ (Chew, Karni and Safra [6]).

Note also that when the transformation function $f$ is convex, it turns out that the set-function $\nu=f o P$ is a convex capacity on $(S, \mathcal{A}): \nu(\emptyset)=0, \nu(S)=1$, $A, B \in \mathcal{A}, A \subset B \Rightarrow \nu(A) \leq \nu(B)$ and (convexity) $\forall A, B \in \mathcal{A}, \nu(A)+\nu(B) \leq$ $\nu(A \cup B)+\nu(A \cap B)$.

Accordingly we will make an extensive use of the following lemma (see Proposition 10.1 in Denneberg [8]):

Lemma 3.1 Let $f$ be a convex probability transformation function. Then for any class $\mathcal{C}$ of (pairwise) comonotonic random variables in $\mathbb{V}$, there exists a probability measure $Q$ on $(S, \mathcal{A}), Q \geq$ foP such that $\forall X \in \mathcal{C}: E_{f o P}(X)=$ $E_{Q}(X)$.

\section{The basic EU-based Consumption/Saving prob- lem}

Let us consider the basic two-period model which has been extensively used since Leland [12] and Sandmo [17], to analyze consumption decisions under risk.

In the first period, the consumer is endowed with a deterministic initial wealth $w$, while his second-period income is risky, represented as a random variable $Y$ with a perfectly known probability distribution. There exists in the economy a technology of storage, which has the main characteristic that one unit of 
consumption today may be transformed in one unit of consumption tomorrow. In words, the access to this technology implies no transaction costs, no loss of initial value but also proceeds no additional value.

Hence, when the agent uses this storage technology, everything goes as if he may save part of his current income and is rewarded with a risk-free interest rate equal to zero. Assume that the preferences of the agent respect the axioms of the EU model, with a time-additively separable representation.

Denoting $c_{1}$ and $C_{2}$ respectively the first-period and second-period consumption levels, the intertemporal utility of the consumer is denoted: $U\left(c_{1}, C_{2}\right)=v\left(c_{1}\right)+$ $E u\left(C_{2}\right)$.

The consumption/saving problem of the agent corresponds to the choice of $x \in[0, w]$ so as to maximize $v(w-x)+E u(Y+x)$.

We assume that $u$ and $v$ the two consumption utility functions are real-valued, defined on $\mathbb{R}^{+}$and satisfy the following assumptions:

\section{Assumption 4.1 :}

i) $v$ is two times continuously differentiable, with $v^{\prime}>0$ and $v^{\prime \prime} \leq 0$;

ii) $u$ is three times continuously differentiable, with $u^{\prime}>0$ and $u^{\prime \prime} \leq 0$;

iii) $u$ or $v$ is strictly concave.

These assumptions are quite natural in the present context:

4.1i) implies that more consumption today is always desirable and that the marginal utility of money today is decreasing, which appears as a usual assumption under certainty.

4.1ii) means that more consumption tomorrow is also always desirable, but that more risk is never desirable: since Drèze and Modigliani [9], it is well known that when he is facing a set of such temporal lotteries $\left(c_{1}, C_{2}\right)$, the DM's attitude towards risk is embedded only through the assumption made on the curvature of the second period utility function (assuming a time-additively separable representation of the preferences). Hence, the DM is risk averse if and only if $u$ is concave. Apart a long stream of controversies on this point, it is worth noting that the concavity of both utility functions may also be usefully justified, at least from an economically meaningful point of view, on the ground that it guarantees the positivity of the income effects. In other words, $v^{\prime \prime} \leq 0$ is required soon as we assume that the second period consumption is a normal good, while $u^{\prime \prime} \leq 0$ insures that the first period consumption is also a normal good.

Finally, 4.1iii) appears as technically useful and tractable. To see this point, denote:

$$
g(x)=v(w-x)+E u(Y+x) .
$$

On the one hand, from the continuity of $u$ and $v$ in $\mathbb{R}^{+}$, we conclude that $g$ is also continuous in $[0, w]$. On the second hand, from 4.1iii) we conclude that $g$ is strictly concave in $[0, w]$. As a result, $g$ has a unique maximum on $[0, w]$. Hence under 4.1, the basic consumption/saving problem is well behaved and 
has a unique solution.

In this problem, the DM obtains through his savings decision a perfect control as far as his first period consumption level is concerned: $c_{1}$ is a deterministic variable. But in contrast, the decision to save, even when saving the full amount of the current income, gives him only a partial control of the second period consumption level: $C_{2}$ is a random variable, contingent on the realization of the risky income. Hence, the desire to smooth the intertemporal consumption may not be the unique motive of savings here. In order to hedge against the second period income risk (and possibly the most defavorable realizations of the future income), the DM may also display a precautionary saving motive.

Kimball [11] proposes to define as a prudent DM any individual who displays a positive motive for precautionary savings - that is: a prudent DM increases his savings when the risk on his future income increases.

Formally, denote $x^{*}(Y, w)$ (respectively $x^{*}(\tilde{Y}, w)$ ) the DM's amount of optimal savings when his future income is $Y$ (respectively $\tilde{Y}$ ) and his initial wealth is $w$. Then:

Definition 4.4 The individual is prudent if $\forall Y, \tilde{Y} \in \mathbb{V}$, such that $\tilde{Y} M P I R Y$ and $\forall w \geq 0$ then $x^{*}(\tilde{Y}, w) \geq x^{*}(Y, w)$.

Since Leland [12], Drèze and Modigliani [9] and Sandmo [17], it is well known that the convexity of the (second period) marginal utility (i.e. $u^{\prime \prime \prime}>0$ ) is a sufficient condition to obtain that a risk averse DM has a positive precautionary saving motive. For his own, Kimball [11] argues in a stimulating paper that there is an isomorphism between the concept of risk aversion and the concept of prudence that may be fruitfully exploited. Then, he suggests that in order to evaluate the intensity of the precautionary saving motive, it may be possible (for a small zero-mean income risk) to define a precautionary premium $\Psi(\varepsilon, x)=$ $\left(-\frac{u^{\prime \prime \prime}(x)}{u^{\prime \prime}(x)}\right) \frac{\sigma_{\varepsilon}^{2}}{2}$ where $\left(-\frac{u^{\prime \prime \prime}(x)}{u^{\prime \prime}(x)}\right)$ is an index of prudence.

Nevertheless, the necessity of the convexity of $u^{\prime}$ has not yet been proved. In the following propositions, we proceed in two steps. First, we show that in the case where $v=u$, the condition $u^{\prime \prime \prime} \geq 0$ is necessary and sufficient for prudence. Then, in the general case where $v \neq u$, we consider two cases for which the DM will be prudent whatever the sign of $u^{\prime \prime \prime}$ is.

Assumption $4.2 v=u$.

Proposition 4.1 Under assumptions 4.1 and 4.2, the DM is prudent if and only if $u^{\prime \prime \prime} \geq 0$.

Before proceeding with the proof, let us denote, for all $Y$ and $\tilde{Y}$ in $\mathbb{V}$ :

$g(x)=v(w-x)+E u(Y+x)$ and $h(x)=v(w-x)+E u(\tilde{Y}+x)$, for all $x \in[0, w]$.

Proof

$(\Rightarrow)$ 
Let us consider the following alternative distribution functions for the second period income: $\mathcal{L}(\tilde{Y})=\left(a, \frac{1}{2} ; b, \frac{1}{2}\right)$ and $\mathcal{L}(Y)=\left(\frac{1}{2} a+\frac{1}{2} b, 1\right)$. Trivially, $\tilde{Y} M P I R$ $Y$.

Since $u^{\prime}$ is continuous, to prove that $u^{\prime \prime \prime} \geq 0$, it is enough to prove that:

$$
\forall a, b \in \mathbb{R}, u^{\prime}\left(\frac{1}{2} a+\frac{1}{2} b\right) \leq \frac{1}{2} u^{\prime}(a)+\frac{1}{2} u^{\prime}(b) .
$$

Define respectively $g$ and $h$ on $[0, w]$, by :

$g(x)=u(w-x)+u\left(\frac{1}{2} a+\frac{1}{2} b+x\right)$ and $h(x)=u(w-x)+\frac{1}{2} u(a+x)+\frac{1}{2} u(b+x)$. Hence, $g^{\prime}(0)=-u^{\prime}(w)+u^{\prime}\left(\frac{1}{2} a+\frac{1}{2} b\right)$ and $h^{\prime}(0)=-u^{\prime}(w)+\frac{1}{2} u^{\prime}(a)+\frac{1}{2} u^{\prime}(b)$.

Let $\epsilon>0$ and take $w=\frac{1}{2} a+\frac{1}{2} b+\epsilon$. Since $u$ is strictly concave, $g^{\prime}(0)>0$, and therefore $x^{*}(Y, w)>0$.

If $h^{\prime}(0)<0$, since $h$ is strictly concave, $x^{*}(\tilde{Y}, w)=0$. Therefore $h^{\prime}(0) \geq 0$, that is $u^{\prime}\left(\frac{1}{2} a+\frac{1}{2} b+\epsilon\right) \leq \frac{1}{2} u^{\prime}(a)+\frac{1}{2} u^{\prime}(b)$, for all $\epsilon>0$. Now by continuity of $u^{\prime}$, when $\epsilon$ tends to 0 we have: $u^{\prime}\left(\frac{1}{2} a+\frac{1}{2} b\right) \leq \frac{1}{2} u^{\prime}(a)+\frac{1}{2} u^{\prime}(b), \forall a, b \in \mathbb{R}$. Therefore $u^{\prime}$ is convex.

$(\Leftarrow)$

Assume $u^{\prime \prime \prime} \geq 0$. If $x^{*}(Y, w)=0$, the result is trivial.

Assume that $x^{*}(Y, w) \in(0, w]$. Given that $g$ is strictly concave, then $g^{\prime}(x)>0$, $\forall x \in\left[0, x^{*}(Y, w)\right)$. To show that $x^{*}(Y, w) \leq x^{*}(\tilde{Y}, w)$, it remains to prove that $h^{\prime}(x)>0, \forall x \in\left[0, x^{*}(Y, w)\right)$. Since $\tilde{Y} M P I R Y$, then $\tilde{Y}+x M P I R Y+x$, $\forall x \in[0, w]$. By hypotheses (i.e.: $u$ concave and $u^{\prime \prime \prime} \geq 0$ ), we obtain that $-u^{\prime}$ is increasing and concave.

Hence, $\forall x \in[0, w], E\left(-u^{\prime}(Y+x)\right) \geq E\left(-u^{\prime}(\tilde{Y}+x)\right)$. Therefore, $E u^{\prime}(Y+x) \leq$ $E u^{\prime}(\tilde{Y}+x)$. Adding both sides with $-u^{\prime}(w-x)$, we obtain: $g^{\prime}(x) \leq h^{\prime}(x), \forall x \in$ $[0, w]$, hence: $h^{\prime}(x)>0, \forall x \in\left[0, x^{*}(Y)\right)$. As a result, $x^{*}(\tilde{Y}, w) \geq x^{*}(Y, w)$.

Now, we consider two alternative cases where the DM is prudent whatever the sign of $u^{\prime \prime \prime}$ is.

Proposition 4.2 Under assumption 4.1, if $\sup v^{\prime}<\inf u^{\prime}$, then the DM is prudent.

Proof

Take $X$ in $\mathbb{V}, w>0$ and $x \in \mathbb{R}$, hence $E u^{\prime}(X+x) \geq \inf u^{\prime}$, and since $\inf u^{\prime}>$ $\sup v^{\prime}, E u^{\prime}(X+x)>v^{\prime}(w-x)$. That is $g^{\prime}(x)=-v^{\prime}(w-x)+E u^{\prime}(X+x)>0$ for all $x \in[0, w]$, therefore $x^{*}(X, w)=w$. As a result, the individual is always prudent.

\section{Example 1:}

Take $u: \mathbb{R}^{+} \rightarrow \mathbb{R}$ defined by $u(x)=x-(x+2) \exp (-x)$ and let $v: \mathbb{R}^{+} \rightarrow \mathbb{R}$ defined by $v(x)=-\frac{1}{2} \exp (-x) ; u$ and $v$ satisfy assumption 4.1. One obtains $1=\inf u^{\prime}>\sup v^{\prime}=\frac{1}{2}$, but $u^{\prime \prime \prime} \geq 0$ if $x \geq 1$, and $u^{\prime \prime \prime} \leq 0$ if $x \in[0,1)$.

Proposition 4.3 Under assumption 4.1, if $\sup u^{\prime}<\inf v^{\prime}$, then the DM is prudent. 
Proof

Take $X$ in $\mathbb{V}, w>0$ and $x \in \mathbb{R}$, hence $E u^{\prime}(X+x) \leq \sup u^{\prime}$, and since $\sup u^{\prime}<$ $\inf v^{\prime}, E u^{\prime}(X+x)<v^{\prime}(w-x)$. That is $g^{\prime}(x)=-v^{\prime}(w-x)+E u^{\prime}(X+x)<0$, for all $x \in[0, w]$, therefore $x^{*}(X, w)=0$. As a result, the individual is always prudent.

Example 2:

Take $u: \mathbb{R}^{+} \rightarrow \mathbb{R}$ defined by $u(x)=-\frac{1}{2}(x+2) \exp (-x)$ and $v: \mathbb{R}^{+} \rightarrow \mathbb{R}$, defined by $v(x)=x-\exp (-x) ; u$ and $v$ satisfy assumption 4.1. One obtains $1=\inf v^{\prime}>\sup u^{\prime}=\frac{1}{2}$, but $u^{\prime \prime \prime} \geq 0$ if $x \geq 1$, and $u^{\prime \prime \prime}<0$ if $x \in[0,1)$.

Propositions 4.2 and 4.3 exhibit two alternative sets of assumptions for which the savings decision of a risk averse DM is defined as a corner solution for the problem of maximizing his intertemporal utility function. Truly speaking, in both instances, the DM's optimal saving level is independent of the future income riskiness. Nevertheless, the DM is said to be prudent in the common sense of the literature, since he does not reduce his savings when the risk associated to his second period income increases, the amount of saving is constant (either $w$ or 0$)$.

\section{The RDEU-based consumption/saving problem}

Assume now that the DM's preferences over temporal lotteries $\left(c_{1}, C_{2}\right)$ satisfy the RDEU axioms, and admit a time-additively separable representation given by:

$$
V\left(c_{1}, C_{2}\right)=v\left(c_{1}\right)+E_{f o P} u\left(C_{2}\right) .
$$

We firstly establish that $u^{\prime \prime \prime} \geq 0$ is sufficient for prudence, although the convexity of $f$ is at the same time required. In other words, if the DM is risk averse in the strong sense and if his (second period) marginal utility is convex, then he is prudent.

Proposition 5.4 Under assumption 4.1, assume that $f$ and $u^{\prime}$ are convex, then the DM is prudent.

Before proceeding with the proof, let us denote for all $Y, \tilde{Y} \in \mathbb{V}$ and $x \in[0, w]$ : $g(x)=v(w-x)+E_{f o P} u(Y+x)$ and $h(x)=v(w-x)+E_{f o P} u(\tilde{Y}+x)$.

Since $u$ and $-u^{\prime}$ are both non-decreasing, it turns out that $\forall Z \in \mathbb{V}, \forall x \in \mathbb{R}$ $u(x+Z)$ and $-u^{\prime}(x+Z)$ are comonotone, hence from lemma $3.1\left(E_{f o P} u(Z+\right.$ $x))^{\prime}=-E_{f o P}\left(-u^{\prime}(Z+x)\right)$, and therefore $g^{\prime}(x)=-v^{\prime}(w-x)-E_{f o P}\left(-u^{\prime}(Y+x)\right)$ and $h^{\prime}(x)=-v^{\prime}(w-x)-E_{f o P}\left(-u^{\prime}(\tilde{Y}+x)\right)$.

Proof

Let $Y, \tilde{Y} \in \mathbb{V}$, such that $\tilde{Y} \operatorname{MPIR} Y$. If $x^{*}(Y, w)=0$, the result is trivial. 
Assume that $x^{*}(Y, w) \in(0, w]$, since $g$ is strictly concave we have: $g^{\prime}(x)>$ $0, \forall x \in\left[0, x^{*}(Y, w)\right)$. Hence to show that $x^{*}(\widetilde{Y}, w) \geq x^{*}(Y, w)$, it is enough to show that $\forall x \in\left[0, x^{*}(Y, w)\right), h^{\prime}(x)>0$.

By assumption, $-u^{\prime}$ is concave and non-decreasing, and $f$ is convex.

From Chew, Karni and Safra ([6], theorem 2), since for any $x, \tilde{Y}+x M P I R$ $Y+x$ we directly obtain that: $E_{f o P}\left(-u^{\prime}(Y+x)\right) \geq E_{f o P}\left(-u^{\prime}(\tilde{Y}+x)\right)$. Then $-E_{f o P}\left(-u^{\prime}(Y+x)\right) \leq-E_{f o P}\left(-u^{\prime}(\tilde{Y}+x)\right)$. Therefore $h^{\prime}(x) \geq g^{\prime}(x), \forall x \in[0, w]$. As a result, we have: $h^{\prime}(x)>0, \forall x \in\left[0, x^{*}(Y, w)\right)$, which completes the proof.

Assumption $5.3 f$ is continuously differentiable on $[0,1]$.

Proposition 5.5 Under assumptions 4.1, 4.2 and 5.3 the DM is prudent if and only if $f$ and $u^{\prime}$ are both convex.

Before proceeding with the proof of proposition 5.5, it is worth noting that it may be formulated as follows: under assumptions 4.1 and 4.2 , the DM is prudent if and only if he is strictly risk averse in the strong sense and $u^{\prime}$ is convex.

Proof

$(\Rightarrow)$

Let $Y, \tilde{Y} \in \mathbb{V}$ be such that: $\mathcal{L}(Y)=\left(y_{1}, p_{1} ; y_{2}, p_{2} ; y_{3}, p_{3}\right)$, with $0 \leq y_{1}<y_{2}<y_{3}$ and $p_{1}+p_{2}+p_{3}=1$ taking $p_{1}<1, p_{2}>0, p_{3}<1$; and

$\mathcal{L}(\tilde{Y})=\left(y_{1}, p_{1}+\epsilon_{1} ; y_{2}, p_{2}+\epsilon_{2} ; y_{3}, p_{3}+\epsilon_{3}\right)$, where $\epsilon_{1}, \epsilon_{2}, \epsilon_{3} \in \mathbb{R}$ satisfy the following conditions: $\epsilon_{1}+\epsilon_{2}+\epsilon_{3}=0$, and $\epsilon_{1} y_{1}+\epsilon_{2} y_{2}+\epsilon_{3} y_{3}=0$. This implies that:

$$
\left\{\begin{array}{l}
\epsilon_{1}=\epsilon \\
\epsilon_{2}=-\frac{y_{3}-y_{1}}{y_{3}-y_{2}} \epsilon \\
\epsilon_{3}=\frac{y_{2}-y_{1}}{y_{3}-y_{2}} \epsilon
\end{array}\right.
$$

Take now $\epsilon>0$; as a result, $\tilde{Y} M P I R Y$.

$\forall x \in[0, w]:$

$g(x)=u(w-x)+u\left(y_{1}+x\right)+\left[u\left(y_{2}+x\right)-u\left(y_{1}+x\right)\right] f\left(p_{2}+p_{3}\right)+\left[u\left(y_{3}+x\right)-u\left(y_{2}+x\right)\right] f\left(p_{3}\right)$

$h(x)=u(w-x)+u\left(y_{1}+x\right)+\left[u\left(y_{2}+x\right)-u\left(y_{1}+x\right)\right] f\left(p_{2}+p_{3}-\epsilon\right)+\left[u\left(y_{3}+x\right)-u\left(y_{2}+x\right)\right] f\left(p_{3}+\frac{y_{2}-y_{1}}{y_{3}-y_{2}} \epsilon\right)$

Then:

$g^{\prime}(x)=-u^{\prime}(w-x)+u^{\prime}\left(y_{1}+x\right)+\left[u^{\prime}\left(y_{2}+x\right)-u^{\prime}\left(y_{1}+x\right)\right] f\left(p_{2}+p_{3}\right)+\left[u^{\prime}\left(y_{3}+x\right)-u^{\prime}\left(y_{2}+x\right)\right] f\left(p_{3}\right)$

$h^{\prime}(x)=-u^{\prime}(w-x)+u^{\prime}\left(y_{1}+x\right)+\left[u^{\prime}\left(y_{2}+x\right)-u^{\prime}\left(y_{1}+x\right)\right] f\left(p_{2}+p_{3}-\epsilon\right)+\left[u^{\prime}\left(y_{3}+x\right)-u^{\prime}\left(y_{2}+x\right)\right] f\left(p_{3}+\frac{y_{2}-y_{1}}{y_{3}-y_{2}} \epsilon\right)$

For $x=0$, we obtain:

$g^{\prime}(0)=-u^{\prime}(w)+u^{\prime}\left(y_{1}\right)+\left[u^{\prime}\left(y_{2}\right)-u^{\prime}\left(y_{1}\right)\right] f\left(p_{2}+p_{3}\right)+\left[u^{\prime}\left(y_{3}\right)-u^{\prime}\left(y_{2}\right)\right] f\left(p_{3}\right)$

$h^{\prime}(0)=-u^{\prime}(w)+u^{\prime}\left(y_{1}\right)+\left[u^{\prime}\left(y_{2}\right)-u^{\prime}\left(y_{1}\right)\right] f\left(p_{2}+p_{3}-\epsilon\right)+\left[u^{\prime}\left(y_{3}\right)-u^{\prime}\left(y_{2}\right)\right] f\left(p_{3}+\frac{y_{2}-y_{1}}{y_{3}-y_{2}} \epsilon\right)$ 


$$
\begin{aligned}
-E_{f o P}\left(-u^{\prime}(Y)\right) & =u^{\prime}\left(y_{1}\right)+\left[u^{\prime}\left(y_{2}\right)-u^{\prime}\left(y_{1}\right)\right] f\left(p_{2}+p_{3}\right)+\left[u^{\prime}\left(y_{3}\right)-u^{\prime}\left(y_{2}\right)\right] f\left(p_{3}\right) \\
& =u^{\prime}\left(y_{1}\right)\left(1-f\left(p_{2}+p_{3}\right)\right)+u^{\prime}\left(y_{2}\right)\left(f\left(p_{2}+p_{3}\right)-f\left(p_{2}\right)\right)+u^{\prime}\left(y_{3}\right) f\left(p_{3}\right)
\end{aligned}
$$

$-E_{f o P}\left(-u^{\prime}(Y)\right) \in\left[u^{\prime}\left(y_{3}\right), u^{\prime}\left(y_{1}\right)\right]$. Since $u^{\prime}$ is continuous, $\exists w \in\left[y_{1}, y_{3}\right]$ such that

$u^{\prime}(w)=-E_{f o P}\left(-u^{\prime}(Y)\right)$

Let $w_{n}=w+\frac{1}{n}>w, \forall n \in \mathbb{N}^{*}, w_{n} \rightarrow w$

For $n \in \mathbb{N}^{*}$, we have $g^{\prime}(0)=-u^{\prime}\left(w_{n}\right)+u^{\prime}(w)>0$, since $u^{\prime}$ is strictly decreasing.

By assumption of prudence $\left(x^{*}(\tilde{Y}, w) \geq x^{*}(Y, w)\right)$, we obtain $h^{\prime}(0)>0$, hence:

$u^{\prime}\left(w_{n}\right)<u^{\prime}\left(y_{1}\right)+\left[u^{\prime}\left(y_{2}\right)-u^{\prime}\left(y_{1}\right)\right] f\left(p_{2}+p_{3}-\epsilon\right)+\left[u^{\prime}\left(y_{3}\right)-u^{\prime}\left(y_{2}\right)\right] f\left(p_{3}+\frac{y_{2}-y_{1}}{y_{3}-y_{2}} \epsilon\right)$

When $n \rightarrow \infty$, we have:

$-E_{f o P}\left(-u^{\prime}(Y)\right) \leq u^{\prime}\left(y_{1}\right)+\left[u^{\prime}\left(y_{2}\right)-u^{\prime}\left(y_{1}\right)\right] f\left(p_{2}+p_{3}-\epsilon\right)+\left[u^{\prime}\left(y_{3}\right)-u^{\prime}\left(y_{2}\right)\right] f\left(p_{3}+\frac{y_{2}-y_{1}}{y_{3}-y_{2}} \epsilon\right)$.

Given the differentiability of $f$, the first order Taylor formula gives:

$f\left(p_{2}+p_{3}-\epsilon\right)=f\left(p_{2}+p_{3}\right)-\epsilon f^{\prime}\left(p_{2}+p_{3}\right)+o_{1}(\epsilon)$.

$f\left(p_{3}+\frac{y_{2}-y_{1}}{y_{3}-y_{2}} \epsilon\right)=f\left(p_{3}\right)+\frac{y_{2}-y_{1}}{y_{3}-y_{2}} \epsilon f^{\prime}\left(p_{3}\right)+o_{2}(\epsilon)$.

Then we obtain:

$-\epsilon f^{\prime}\left(p_{2}+p_{3}\right)\left[u^{\prime}\left(y_{2}\right)-u^{\prime}\left(y_{1}\right)\right]+\frac{y_{2}-y_{1}}{y_{3}-y_{2}} \epsilon f^{\prime}\left(p_{3}\right)\left[u^{\prime}\left(y_{3}\right)-u^{\prime}\left(y_{2}\right)\right]+\epsilon \alpha(\epsilon) \geq 0$, where $\lim _{\epsilon \rightarrow 0} \alpha(\epsilon)=0$.

Dividing by $\epsilon>0$ and letting $\epsilon$ tend to zero, we obtain:

$$
\frac{y_{2}-y_{1}}{y_{3}-y_{2}} f^{\prime}\left(p_{3}\right)\left[u^{\prime}\left(y_{3}\right)-u^{\prime}\left(y_{2}\right)\right] \geq f^{\prime}\left(p_{2}+p_{3}\right)\left[u^{\prime}\left(y_{2}\right)-u^{\prime}\left(y_{1}\right)\right]
$$

By continuity of $f^{\prime}$, when $p_{2} \rightarrow 0$ and $p_{3}$ is chosen such that $f^{\prime}\left(p_{3}\right)>0$ we have:

$$
\frac{u^{\prime}\left(y_{2}\right)-u^{\prime}\left(y_{1}\right)}{y_{2}-y_{1}} \leq \frac{u^{\prime}\left(y_{3}\right)-u^{\prime}\left(y_{2}\right)}{y_{3}-y_{2}} .
$$

therefore, $u^{\prime}$ is convex.

Now, let us consider the inequality (I), and let us take simultaneously $y_{3} \rightarrow y_{2}$ and $y_{1} \rightarrow y_{2}$. Since $u$ is twice differentiable, we obtain:

$$
f^{\prime}\left(p_{2}+p_{3}\right) u^{\prime \prime}\left(y_{2}\right) \leq f^{\prime}\left(p_{3}\right) u^{\prime \prime}\left(y_{2}\right)
$$

By strict concavity of $u$, we may assume $y_{2}$ chosen such that $u^{\prime \prime}\left(y_{2}\right)<0$, therefore $f^{\prime}\left(p_{3}+p_{2}\right) \geq f^{\prime}\left(p_{3}\right)$ which means that:

$f^{\prime}(q) \geq f^{\prime}(p), \forall 0 \leq p<q \leq 1$, hence $f$ is convex.

$(\Leftarrow)$ The proof for sufficiency is the same as in proposition 5.4. 
Assumption 5.4 (Inada Conditions for $v$ ) $v^{\prime}(0)=\infty$ and $v^{\prime}(\infty)=0$.

Proposition 5.6 Under assumptions 4.1, 5.3 and 5.4, the DM is prudent if and only if $f$ and $u^{\prime}$ are both convex.

Once more, before proceeding with the proof of proposition 5.6, it is worth noting that it may be formulated as follows: under assumptions 4.1, 5.3 and 5.4 , the DM is prudent if and only if he is risk averse in the strong sense and $u^{\prime}$ (second period marginal utility) is convex.

Proof

$(\Rightarrow)$

Consider $Y, \widetilde{Y} \in \mathbb{V}$ as in the proof of proposition 5.5, we choose $y_{2}$ such that $u^{\prime \prime}\left(y_{2}\right)<0, \tilde{Y} M P I R Y$.

Define $\forall x \in[0, w]$ :

$g(x)=v(w-x)+u\left(y_{1}+x\right)+\left[u\left(y_{2}+x\right)-u\left(y_{1}+x\right)\right] f\left(p_{2}+p_{3}\right)+\left[u\left(y_{3}+x\right)-u\left(y_{2}+x\right)\right] f\left(p_{3}\right)$

$h(x)=v(w-x)+u\left(y_{1}+x\right)+\left[u\left(y_{2}+x\right)-u\left(y_{1}+x\right)\right] f\left(p_{2}+p_{3}-\epsilon\right)+\left[u\left(y_{3}+x\right)-u\left(y_{2}+x\right)\right] f\left(p_{3}+\frac{y_{2}-y_{1}}{y_{3}-y_{2}} \epsilon\right)$

So:

$g^{\prime}(x)=-v^{\prime}(w-x)+u^{\prime}\left(y_{1}+x\right)+\left[u^{\prime}\left(y_{2}+x\right)-u^{\prime}\left(y_{1}+x\right)\right] f\left(p_{2}+p_{3}\right)+\left[u^{\prime}\left(y_{3}+x\right)-u^{\prime}\left(y_{2}+x\right)\right] f\left(p_{3}\right)$

$h^{\prime}(x)=-v^{\prime}(w-x)+u^{\prime}\left(y_{1}+x\right)+\left[u^{\prime}\left(y_{2}+x\right)-u^{\prime}\left(y_{1}+x\right)\right] f\left(p_{2}+p_{3}-\epsilon\right)+\left[u^{\prime}\left(y_{3}+x\right)-u^{\prime}\left(y_{2}+x\right)\right] f\left(p_{3}+\frac{y_{2}-y_{1}}{y_{3}-y_{2}} \epsilon\right)$

For $x=0$, we obtain:

$$
\begin{aligned}
g^{\prime}(0) & =-v^{\prime}(w)-E_{f o P}\left(-u^{\prime}(Y)\right) \\
& =-v^{\prime}(w)+u^{\prime}\left(y_{1}\right)+\left[u^{\prime}\left(y_{2}\right)-u^{\prime}\left(y_{1}\right)\right] f\left(p_{2}+p_{3}\right)+\left[u^{\prime}\left(y_{3}\right)-u^{\prime}\left(y_{2}\right)\right] f\left(p_{3}\right) \\
h^{\prime}(0) & =-v^{\prime}(w)+u^{\prime}\left(y_{1}\right)+\left[u^{\prime}\left(y_{2}\right)-u^{\prime}\left(y_{1}\right)\right] f\left(p_{2}+p_{3}-\epsilon\right)+\left[u^{\prime}\left(y_{3}\right)-u^{\prime}\left(y_{2}\right)\right] f\left(p_{3}+\frac{y_{2}-y_{1}}{y_{3}-y_{2}} \epsilon\right)
\end{aligned}
$$

Since, $u$ and $f$ are increasing, then $-E_{f o P}\left(-u^{\prime}(Y)\right)>0$.

By assumption 5.4 and continuity of $v^{\prime}$, there exists a sequence $w_{n}>0$ such that: $c_{n}=v^{\prime}\left(w_{n}\right)<-E_{f o P}\left(-u^{\prime}(Y)\right)$ and $c_{n} \uparrow-E_{f o P}\left(-u^{\prime}(Y)\right)$.

As a result, $\forall w_{n}$ we have: $g^{\prime}(0)>0$. On the other hand, by assumption of prudence $\left(x^{*}(\tilde{Y}, w) \geq x^{*}(Y, w)\right)$, we obtain $h^{\prime}(0)>0$; hence:

$v^{\prime}\left(w_{n}\right)<u^{\prime}\left(y_{1}\right)+\left[u^{\prime}\left(y_{2}\right)-u^{\prime}\left(y_{1}\right)\right] f\left(p_{2}+p_{3}-\epsilon\right)+\left[u^{\prime}\left(y_{3}\right)-u^{\prime}\left(y_{2}\right)\right] f\left(p_{3}+\frac{y_{2}-y_{1}}{y_{3}-y_{2}} \epsilon\right)$

When $n \rightarrow \infty$, we have:

$-E_{f o P}\left(-u^{\prime}(Y)\right) \leq u^{\prime}\left(y_{1}\right)+\left[u^{\prime}\left(y_{2}\right)-u^{\prime}\left(y_{1}\right)\right] f\left(p_{2}+p_{3}-\epsilon\right)+\left[u^{\prime}\left(y_{3}\right)-u^{\prime}\left(y_{2}\right)\right] f\left(p_{3}+\frac{y_{2}-y_{1}}{y_{3}-y_{2}} \epsilon\right)$

The remainder of the proof is the same one as in proposition 5.5.

$(\Leftarrow)$

The proof for sufficiency is the same as in proposition 5.4. 


\section{The Local Weak Prudence}

The results of the previous sections are based on the notion of mean preserving increase in risk (MPIR), which is usually more relevant when we consider a class of large risks. But some of the well known paradoxes in decision theory appear in the range of small risks. For instance, Arrow [3] has shown that in fact a risk averse EU DM behaves locally in a risk neutral manner, where by locally we mean: facing risky prospects with small variance.

Segal and Spivak [18] define this attitude as second order risk aversion, and they show that in contrast, any RDEU DM, risk averse in the strong sense, displays first order risk aversion (that is, he is also risk averse for small risks).

In this part of the paper, we focus on the precautionary motive for saving when the future income is seen as a small risk, defined as follows.

Let $(a, w) \in \mathbb{R}_{*}^{+2}$ be given, with $a$ a deterministic second period income level. Let $Z$ be a random variable with zero-mean, and consider $a+t Z$ with $t$ small enough such that $a+t Z \geq 0$. Hence, $t Z$ may be seen as a small noise which adds to the determinist future income.

Intuitively speaking, the DM will be in some sense "prudent", if facing with a small actuarially neutral risk, then he increases his savings. We will term this attitude as a locally weakly prudent behavior. Formally:

Definition 6.5 The DM is locally weakly prudent if $\forall(a, w) \in \mathbb{R}_{*}^{+2}, \forall X \in \mathbb{V}$ with $E(Z)=0$, there exists $t_{0}>0$ such that $0<|t| \leq t_{0}$ implies $x^{*}(a+t Z, w) \geq$ $x^{*}(a, w)$.

It is now shown that in the EU model, the individual may not be locally weakly prudent. This is done by constructing a counter-example.

\section{A Counter-example:}

Let $u: \mathbb{R}^{+} \rightarrow \mathbb{R}$ and $v: \mathbb{R}^{+} \rightarrow \mathbb{R}$ defined by:

$u(x)=-1.2(x+2) \exp (-x)$ strictly increasing, strictly concave and $v(x)=x$ strictly increasing, concave and $u^{\prime \prime \prime} \geq 0$ if $x \geq 1, u^{\prime \prime \prime} \leq 0$ if $x \leq 1$.

Let $a=0.5$ and $w=2$ fixed and $\mathcal{L}(Z)=\left(-0.1, \frac{1}{2} ; 0.1, \frac{1}{2}\right), E(Z)=0$. It remains to show that for all $0<t_{0} \leq 5$, there exists $0<|t| \leq t_{0}$ such that $x^{*}(0.5+t Z, 2)<x^{*}(0.5,2)$. For simplicity of notation, denote $x^{*}(0.5,2)=x^{*}$ $g(x)=2-x+u(0.5+x)$, so

$g^{\prime}(x)=-1+u^{\prime}(0.5+x)=-1+1.2(x+1.5) \exp -(x+0.5)$ and

$g^{\prime \prime}(x)=-1.2(x+0.5) \exp -(x+0.5)$

It is very easy to verify that the optimal solution $x^{*}$ of the maximization of $g$ under $x \in[0,2]$ exists, unique and satisfy $g^{\prime}\left(x^{*}\right)=0$, since $g^{\prime}(0)>0$ and $g^{\prime}<2$. Also we can easly check that $0,2<x^{*}<0,3$.

Let us show that $\forall 0<|t| \leq 1, h^{\prime}\left(x^{*}\right)<0$, which will complete the proof. $h(x)=2-x+E u(a+x+t Z)$, then $h^{\prime}(x)=-1+\frac{1}{2} u^{\prime}(0.5+x-0.1 t)+\frac{1}{2} u^{\prime}(0.5+$ $x+0.1 t)$. 
Since $0.5+x^{*}-0.1 t$ and $0.5+x^{*}+0.1 t$ belong in $(0,1)$ and $u^{\prime}$ is strictly concave in $(0,1), h^{\prime}\left(x^{*}\right)<-1+u^{\prime}\left(\frac{0.5+x^{*}-0.1 t+0.5+x^{*}+0.1 t}{2}\right)=-1+u^{\prime}\left(0.5+x^{*}\right)=0$. That is $x^{*}(0.5+t Z, 2)<x^{*}(0.5,2), \forall 0<|t| \leq 1$.

Assume that the preference of the DM respects the RDEU axioms. Consider the additional following assumption:

\section{Assumption 6.5 :}

i) $f^{\prime \prime} \geq 0$ and $f(p)<p \forall p \in(0,1)$.

ii) $u \in C^{2}\left(\mathbb{R}^{+}, \mathbb{R}\right)$ and $u^{\prime \prime}(x)<0, \forall x \in \mathbb{R}^{+}$.

6.5i) says that the DM is strictly pessimistic: this hypothesis is weaker than the strict convexity of $f$, but stronger than strict risk aversion, since the DM is strictly risk averse if and only if $f$ and $u$ are respectively convex and concave, convexity of $f$ or concavity of $u$ being strict.

6.5ii) implies that the utility function of the second period is strictly concave.

Hence, the DM is strictly risk averse in the strong sense, and strictly pessimistic.

Proposition 6.7 Under assumptions 4.1 and 6.5, a RDEU DM is locally weakly prudent.

\section{Proof}

Let us consider $(a, w) \in \mathbb{R}_{*}^{+2}$, and $Z$ a random variable in $\mathbb{V}$ such that $E(Z)=0$ and $t \in \mathbb{R}$ such that $a+t Z \geq 0$. For simplicity of notation, denote $x^{*}(a, w)=x^{*}$ and $x^{*}(a+t Z, w)=\tilde{x}^{*}$.

We intend to prove that there exists $t_{0}>0$ such that $0<|t| \leq t_{0}$ implies $\tilde{x}^{*} \geq x^{*}$.

If $x^{*}=0$, the result is trivial.

Assume that $x^{*} \in(0, w]$. Let us define, $\forall x \in[0, w]$ :

$g(x)=v(w-x)+u(a+x) \quad$ and $\quad h(x)=v(w-x)+E_{f o P} u(a+x+t Z)$.

Clearly $g^{\prime}(x)=-v^{\prime}(w-x)+u^{\prime}(a+x)$.

First suppose that $t>0$ is chosen small enough such that $a+t Z \geq 0$.

Since for $t>0$, the class $\mathcal{C}$ of random variables defined by: $Z$ and $u(a+x+t Z)$, is a class of comonotonic random variables, from lemma 3.1 there exists a probability $Q, Q \geq f o P$, such that $E_{f o P}(Z)=E_{Q}(Z)$ and $E_{f o P} u(a+x+t Z)=$ $E_{Q} u(a+x+t Z)$ for such a small $t>0$.

It turns out that $h^{\prime}(x)=-v^{\prime}(w-x)+E_{Q} u^{\prime}(a+x+t Z)$.

Let $[m, M]$ be the range of $Z$, hence from the Taylor formula applied to $z \in$ $[m, M]$ :

$u^{\prime}(a+x+t z)=u^{\prime}(a+x)+t z u^{\prime \prime}(a+x)+\frac{(t z)^{2}}{2} u^{\prime \prime \prime}\left(a+x+\theta_{z} \cdot t z\right) ; \theta_{z} \in(0,1)$.

Since $u^{\prime \prime \prime}$ is continuous hence bounded on $[0, a+x+M]$, it comes:

$E_{Q} u^{\prime}(a+x+t Z)=u^{\prime}(a+x)+t\left[E^{Q}(Z) u^{\prime \prime}(a+x)+\epsilon(t)\right]$, with $\epsilon(t) \rightarrow 0$, where $t \rightarrow$

$0^{+}$. Given that $f(p)<p, \forall p \in(0,1)$, we know that $E_{f o P}(Z)<E_{P}(Z)=0$ 
(Quiggin [15], Chateauneuf and Cohen [5]), i.e. $E_{Q}(Z)<0$.

Since $u^{\prime \prime}\left(a+x^{*}\right)<0$ it is obvious that there exists $t_{1}>0$ such that: $0<t \leq t_{1}$ implies $E_{Q} u^{\prime}\left(a+x^{*}+t Z\right)>u^{\prime}\left(a+x^{*}\right)$, hence $h^{\prime}\left(x^{*}\right)>0$.

Let us now suppose that $t<0$ is chosen small enough such that $a+t Z \geq 0$.

Pairwise comonotonicity of $-Z$ and $u(a+x+t Z), t<0$, implies from lemma 3.1 the existence of a probability $Q, Q \geq f o P$, such that: $E_{f o P}(-Z)=E_{Q}(-Z)$ and $E_{f o P} u(a+x+t Z)=E_{Q} u(a+x+t Z)$ for $t<0$ small enough.

The same reasoning as above gives: $h^{\prime}(x)=-v^{\prime}(w-x)+E_{Q} u^{\prime}(a+x+t Z)$ and $E_{Q} u^{\prime}(a+x+t Z)=u^{\prime}(a+x)+(-t)\left[E^{Q}(-Z) u^{\prime \prime}(a+x)+\epsilon(t)\right]$, with $\epsilon(t) \rightarrow$ 0 , where $t \rightarrow 0^{-}$.

Again $f(p)<p, \forall p \in(0,1)$ implies $E_{f o P}(-Z)<E_{P}(-Z)=0$, i.e. $E_{Q}(-Z)<$ 0 .

Since $u^{\prime \prime}\left(a+x^{*}\right)<0$ it is clear that there exists $t_{2}>0$ such that: $0<-t \leq t_{2}$ implies $E_{Q} u^{\prime}\left(a+x^{*}+t Z\right)>u^{\prime}\left(a+x^{*}\right)$, hence $h^{\prime}\left(x^{*}\right)>0$.

Take $t_{0}=\min \left(t_{1}, t_{2}\right)$, we have $0<|t| \leq t_{0}$ implies $h^{\prime}\left(x^{*}\right)>0$. That is $0<|t| \leq t_{0}$ implies $\tilde{x}^{*} \geq x^{*}$, which completes the proof.

\section{Concluding remarks}

The concept of prudence is at least as popular as the concept of risk aversion among economists. Nevertheless, it seems that it had not yet received so robust foundations, and as a matter of fact, there did not exist a complete charaterization of this behavioral assumption even in the classical context of the expected utility model. It is obvious that the previous analysis of the prudence, focusing on the precautionary motive for savings, provide only sufficient conditions - not necessary conditions, for prudent behaviors to exist.

This paper was an attempt to fulfil this gap, and successfully affords a complete characterization of prudence both in the EU model and in the RDEU framework. We have considered the basic two-period consumption/saving problem where the DM is facing a risky income in second period, and where his first and second period consumption utility, respectively $v$ and $u$, are assumed to be concave. When the usual assumption according to which $u=v$ is introduced, we have shown that prudence is fully characterized by the convexity of $u^{\prime}$ in the EU model, while we have proven that for the RDEU model, prudence is fully characterized by the convexity of $u^{\prime}$ and strong pessimism. Interestingly enough, we have shown through two sensible examples that, relaxing the assumption $u=v$, the convexity of $u^{\prime}$ is neither necessary nor sufficient in a EU context to obtain a prudent behavior. But, in the RDEU model, we obtain that strong pessimism and the convexity of $u^{\prime}$ are necessary and sufficient for prudence when $u \neq v$, as far as the first period utility function is well behaved (respects Inada conditions).

Although the paper mainly considers the case of a large income risk, understood in the sense of mean preserving increase in risk (MPIR), we also adress the issue of prudence in the case of a small (actuarially neutral) risk in the sense of Arrow [2]. This has allowed us to introduce the concept of local weak prudence, attended to parallel the analysis of first order risk aversion in the 
sense of Segal and Spivak [18]. The paper finally has shown that for a strong risk averse RDEU decision maker, strict pessimism allows local weak prudence, whatever the sign of $u^{\prime \prime \prime}$.

\section{References}

[1] Allais, M. (1988): The General Theory of Random Choices In Relation to The Invariant Cardinal Utility Function and The Specific Probability Function. in Risk, Decision and Rationality, Ed. B. Munier. p 233-289.

[2] Arrow, K.J. (1965): The Theory of Risk Aversion, in Aspects of the theory of risk bearing. Yrjoj. Saatio, Helsinki.

[3] Arrow, K.J. (1971): Essays In The Theory OF Risk-Bearing. NorthHolland, Amsterdam.

[4] Chateauneuf, A.(1999): Comonoticity Axioms and RDEU Theory for Arbitrary Consequences, Journal of Mathematical Economics 32(1), 2145 .

[5] Chateauneuf, A., and Cohen, M. (1994): Risk seeking with diminishing marginal utility in a non expected utility model. Journal of Risk and Uncertainty 9, 77-91.

[6] Chew, S., Karni, E., and Safra, Z. (1987): Risk Aversion in The Theory of Expected Utility With Rank Dependent Preferences. Journal of Economic Theory 42, 370-381.

[7] Demers, F. and Demers, M. (1992): Saving Under Uncertainty: A Bivariate Non-Ecpected Utility Approach, The Geneva Papers on Risk and Insurance Theory, 17(1), 61-75.

[8] Denneberg, D. (1994): Non-additive Measure and Integral. Theory and Decision Library, Kluwer Academic Publishers.

[9] Drèze, J and Modigliani, F (1972): Consumption Decisions Under Uncertainty. Journal of Economic Theory 5, 308-335.

[10] Etner, J. (1997): Precautionary savings: an element of behavior and economic adjustments analysis, Thèse de Doctorat, Université de Paris 1.

[11] Kimball, M.S. (1990): Precautionary Saving In The Small and In The Large. Econometrica 58, 53-73.

[12] Leland, H.E. (1968): Saving and Uncertainty: The Precautionary Demand For Saving. Quarterly Journal of Economic.

[13] Pratt, J. (1964): Risk Aversion In the Small and In The Large. Journal of Behavior and organization 3, 323-343. 
[14] Quiggin, J. (1982): A Theory of Anticipated Utility. Journal of Economic Behavior and Organization 3, 323-343.

[15] Quiggin, J. (1991): Comparative Static for Rank-Dependent Expected Utility Theory. Journal of Risk and Uncertainty 4, 339-350.

[16] Rothschild, M. and Stiglitz, J.E. (1970): Increasing risk. I. A definition. Journal of Economic Theory 2, 225-243.

[17] Sandmo, A. (1970): The Effect of Uncertainty on Saving Decisions. Review of Economic Studies 37, 353-360.

[18] Segal, U., Spivak, A.(1990): First Order Versus Second Order Risk Aversion. Journal of Economic Theory 51,111-125.

[19] Wakker(1994): Separating marginal utility and risk aversion. Theory and decision, 36, 1-44.

[20] Yaari, M.E. (1987): The Dual Theory of Choice Under Risk. Econometrica 55,95-115. 